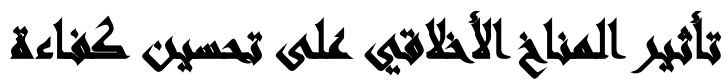

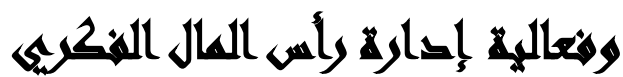

\section{$[r 7]$}

سبد محمود الخولي(')- ماجدة جبريل(') - أحمد فخري هاني(')- فاطمة مصطفى عزوز

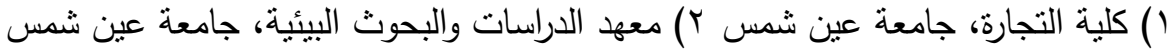

\section{المستخلس}

هدفت هذه الدراسة إلى التعرف على تأثثر المناخ الأخلاقي بأبعادها المختلفة (الرعاية،

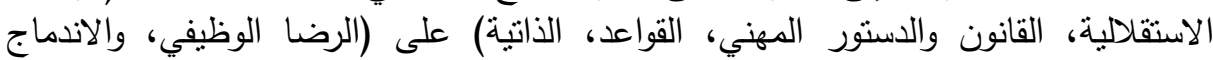

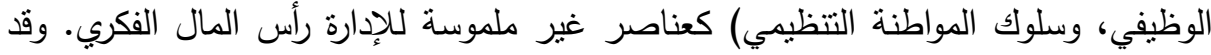

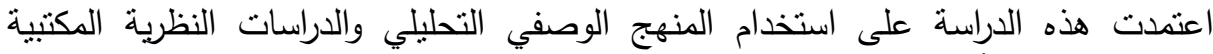
وتضمن البحث أيضا دراسة ميدانية على الجامعات الحكومية بكلياتها المختلفة الكاتية بالقاهرة

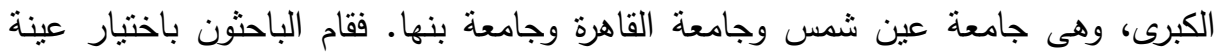

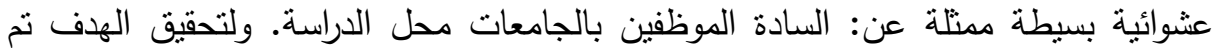

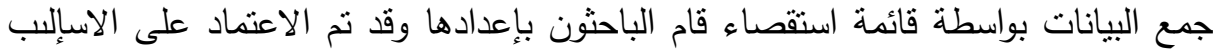

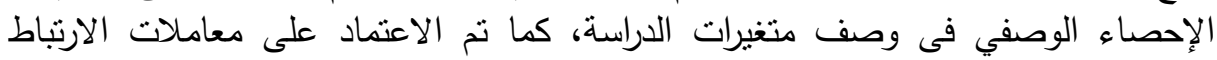
وأسإلب الاتحدار البسيط في اختبار الفرضيات.

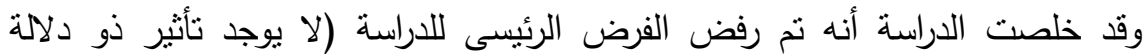

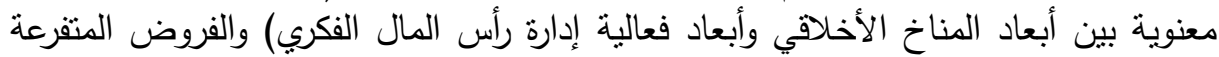

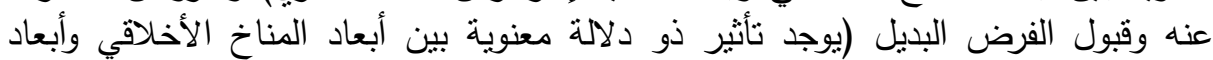
فعالية إدارة رأس المال الفكري).

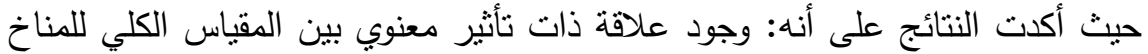

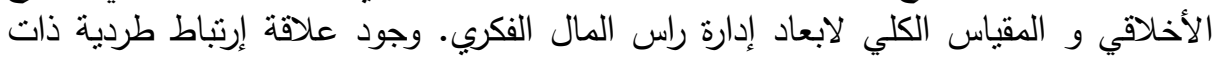
دلاله إحصائية بين المقياس الكلي للمناخ الأخلاقي وبين المقياس الكالى الكلى إدارة راس المال المال الفكري.

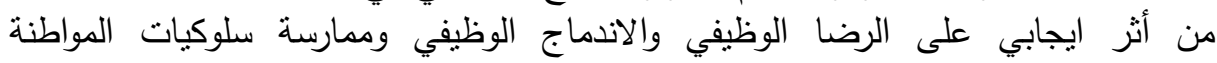
التنظيمي.

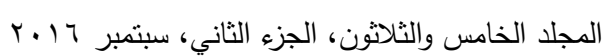




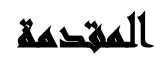

شهد العالم فى السنوات الأخيرة تغيرات جوهرية على صعيد الاقتصاد العالمي، وظهور

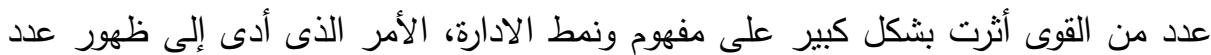
من المداخل والأنظمة والمفاهيم الحديثة لمواكبة تلك المتغيرات وتحقيق السرعة فى التكيف

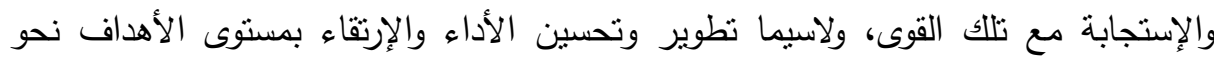
تحقيق الأفضل. لقد أصبح "المناخ الأخلاقى" من المفاهيم الحديثة حيث يعد من المتغيرات الهامة التى تلعب دوراً كبيراً في توفير بيئة سليمة ملائمة لإنجاز الأعمال والمهام بالطريقة

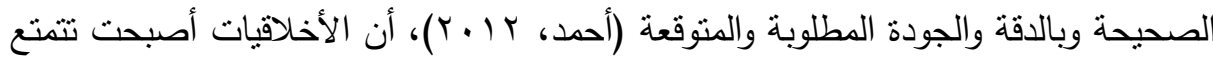
بأهية خاصة في الوقت الحالىى ويرجع ذللك إلى ما ظهر في الآونة الأخيرة من أزمات أخلاقية داخل المنظمات، مما أدى إلى تزايد الوعي لاى العديد من المنظمات بأهمية وجود

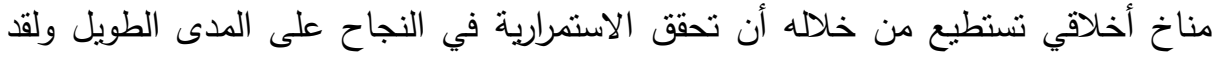
ظهر الأهتمام بالمناخ الأخلاقي للمنظمة على يد (Victor\& Cullen, 1911) حيث أثنارا إلى أن المناخ الأخلافي هو "عبارة عن تصوارت العاملين تجاه الممارسـات والاجراءات والمعايير والقيم السائد داخل المنظمة وذلك من خلال سياق أخلاقي". وترى (دعاء، ب ( ب Y)،

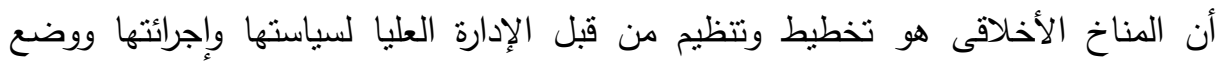

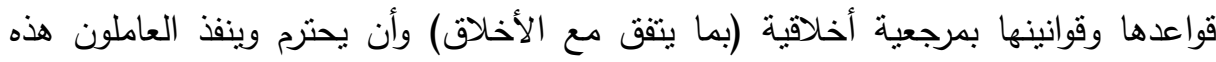
القواعد بشكل أخلاقي تحت قيادة ورقابة أخلاقية. لتحقيق السرعة فى التكيف والأستجابة مع تلك التغيرات، وتحسين كفاءة وفعالية الإدارة والارنقاء بمستوى الأهداف نحو تحقيق الأفضل، لقد أدركت العديد من المنظمات أن القيمة لئهي

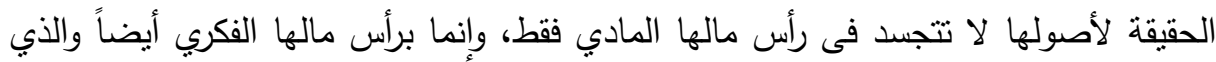
يتمنل بإبداع العاملين ومهاراتهم وإتقان المنظمة وبراءات الاختراع وعلاقاتها مع العملاء.

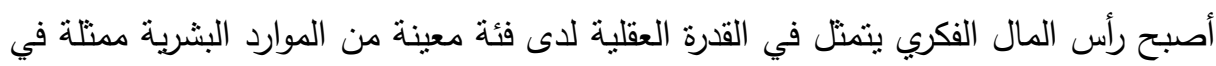
الكفاءات القادرة على توليد الأفكار المتعلقة بالتطوير الخلاق والاستراتيجي للأنظمة والأنشطة والعمليات والاستراتيجيات بما يضمن للمنظمة امتلاك ميزة تتافسية مستدامة (حامد، بـ ب ـ ب).

$$
\text { المجلد الخامس والثنلثثن، الجزء الثاني، سبتمبر } 17 \text { ـ }
$$


تأسيساً على ما سبق فقد أصبح من منطلبات بيئة العمل الحإلبة وما تتسم به من حدة منافسة هو التركيز على مدى ادراك العاملين لأهمية وتأثنير المناخ الأخلاقي في بيئة العمل من لهن التي يعملون فيها وكيفية تتمية رأس مالها الفكري لتحقيق عناصر تتقوق بها على منافسيها سواء كان ذلك على مستوى جودة المنتج أو الخدمة أو على مستوى التكلفة والسعر أو غيرها

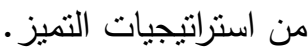

\section{and}

أن أصعب ما يمكن أن تعاني منه المنظمات في الوقت الحالى هو موضوع الأخلاقيات

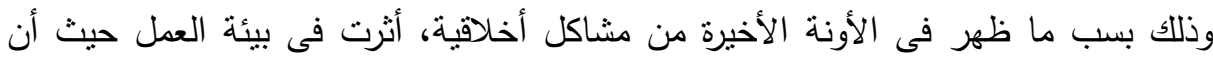

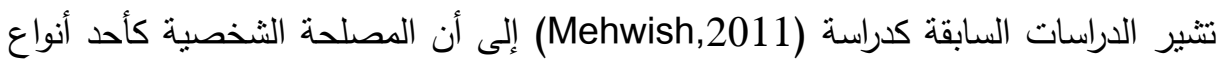

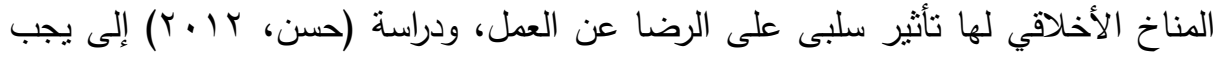
على الإدارة العليا فى المستشفيات الحكومية والخاصة أن تعمل على تدعيم وتعزيز مناخ الخها الرعاية لما له من أثز ايجابى على مدركات هيتُّه التمريض للعدالة التنظمية بابعادها المختلفة.

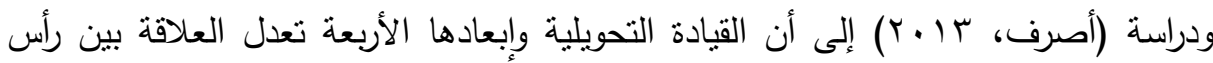
المال الفكري وأبعاد التكيف مع التغيير التتظيمي وتعد هذه النتيجة منطقية حيث انه كلما زادت الدافعية التحويلية كلما زادت درجة التكيف إلى التغيير التتظيمي، لذلك تتمنل مشكلة البحث في "وجود قصور فى ادارة رأس المال الفكري لدى المسئولين بالجامعات متمثل في الرضا الوظيفي والاندماج الوظيفي وسلوك المواطنه التنظيمي، لدى الموظفين كعناصر غير ملموسة لقياس رأس المال الفكري ناتج عن عدم الإهتمام بالمناخ الأخلاقى لدى الموظفين داخل

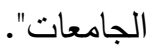
في ضوء ما سبق تتمثل مشكلة الدراسة في الإجابة على التساؤلات التالية.

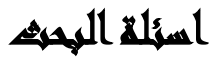

ا ـ ما مدى توافر المناخ الأخلاقي بأبعاده المختلفة داخل الجامعات الحكومية المصرية؟ r. ما مدى تأثنر أبعاد المناخ الأخلاقي على تحسين كفاءة وفعالية إدارة رأس المال الفكري

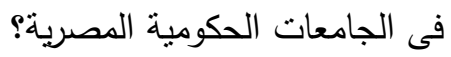

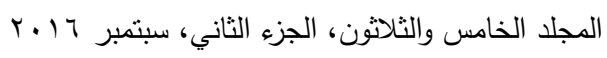




\section{أهمية المهمث}

ا. يرى الباحثون أهمية بالغة فى دارسة الأخلاق بوجه عام، وتطبيقها فى كافة المجالات

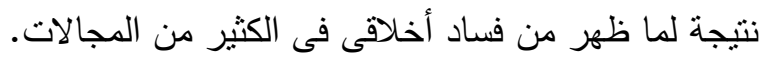

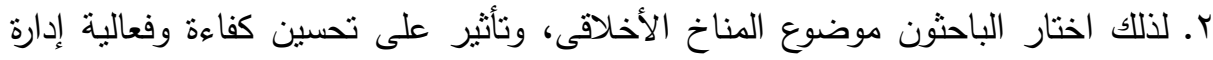

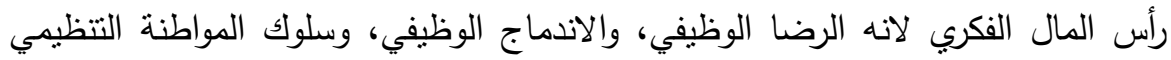
لاى العاملين من الاصوال القيمة وغير الملموسه والمحور الأساسى فى فكر الادارة الجديدة، وتحقيق بيئة ابداعية تنواءم مع متطلبات العصر ، وقادرة على تحقيق الاهداف

$$
\text { وتلبية الطموحات، لدى العاملين بجامعات. }
$$

لذا نأنى اهمية البحث من أهمية وجود مناخ أخلاقى صحي فى ظل المتغيرات البيئية

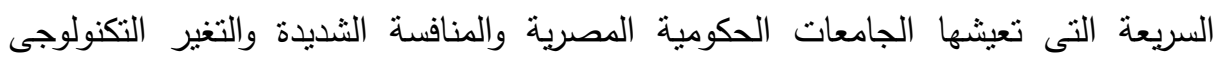
السريع، لكى يعطى الفرصة لنمو الطاقات الابداعية ويشجع التجديد ويمنح العاملين مجالأ اوسع فى العمل والاتصالات واتخاذ القرارات وتحسين فعالية وكفاءة الأداء.

\section{أهساهن الهمهي}

$$
\text { تتركز أهداف الدراسة فيما يلى: }
$$

ا ـ ابراز مفهوم واهمية المناخ الأخلاقي ودوره فى الجامعات المصرية. r. التعرف على دور المناخ الأخلاقي في تحسين كفاءة إدارة رأس المال الفكري بالجامعات. r. دراسة تأثثر عناصر المناخ الأخلاقي من جميع الأبعاد والتي تتمل (الرعاية، الاستقلالية، القانون والدستور المهني، القواعد، الذاتية) على (الرضا الوظيفي، والاندماج الإسياج

الوظيفي، وسلوك المواطنة التنظيمي). ع. اجراء دراسة ميدانية لتأثير المناخ الأخلاقي على فعالية إدارة راس المال الفكري بالتطبيق علي الجامعات المصرية الحكوميه محل الدراسة. 


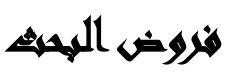

فى ضوء مشكلة وأهداف الدراسة بمكن صياغة الفروض التالنة: الفرض الرئيسى:"لا يوجد تأثثر ذو دلالة معنوية بين أبعاد المناخ الأخلاقي وأبعاد فعالية

$$
\text { الفروض الفرار رأس المال الفكري". }
$$

ا. لا يوجد تأثنير ذو دلالة معنوية بين أبعاد المناخ الأخلاقي والتى تتمنل في الرعاية،

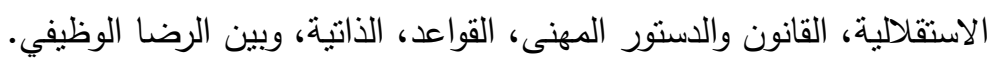

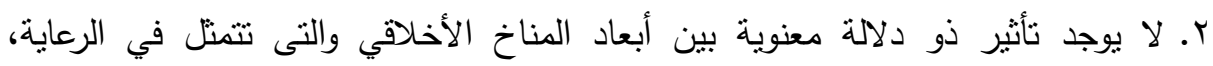

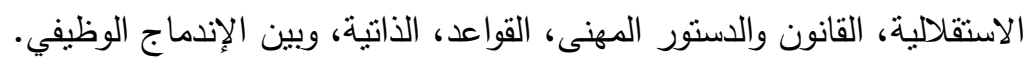

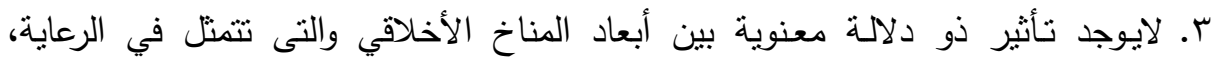
الاستقلالية، القانون والدستور المهنى، القواعد، الذاتية، وبين سلوك المواطنة التتظيمى.

\section{مبورت الهمبه}

الحدود المكانية: اقتصر البحث على بعض الجامعات الحكومية بالقاهرة الكبرى، وهي جامعة عين شمس والقاهرة وبنها. الحدود الزمنية: الحدود الزمنية للقيام بالدراسة الميدانية من خلال الفترة الزمنية من بداية

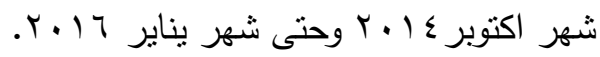

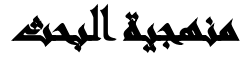

قام الباحثون باتباع المنهج الوصفي لتحقيق الهدف من البحث والتحقق من الفروض كالتإلى : - المنهج الاستقرائي: من خلال الاطلاع على الدراسات السابقة، والكتب العلمية والدوريات العلمية، بهذف التعرف على المشكلة محل البحث.

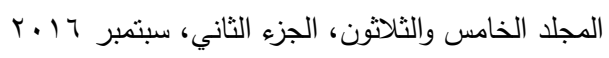


- المنهج الاستدالإلى التحليلي: بهدف تحليل البيانات التي تثبت صحة او عدم صحة الفروض البحثية التي قام عليها البحث.

\section{التواساهت الساريه}

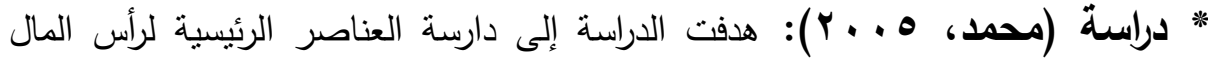

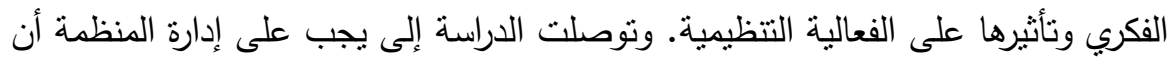

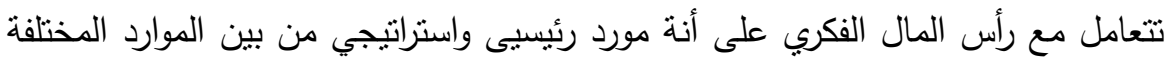
التي تمنلكها المنظمة. * دراسة (Praveen,et.al,2010) تهدف هذه الدراسة إلى معرفة أثز كل من الاتصالات الفعالة وتمكين العاملين على المناخ الأخلاقي للمنظمة. وتوصلت هذه الدراسة

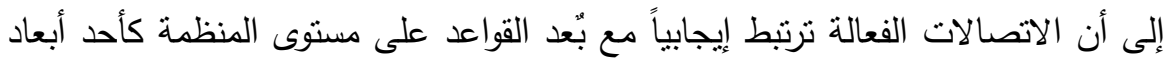

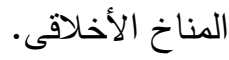

* دراسة (Mehwish,2011) أوضحت هذه الدراسة معرفة الاسباب التى تجعل القطاع العام لا يتبع بالكامل اخلاقيات العمل. وتوصلت هذه الدراسة إلى أن المصلحة الثخصية كأحد أنواع المناخ الأخلاقي لها تأثير سلبى على الرضات عن العمل.

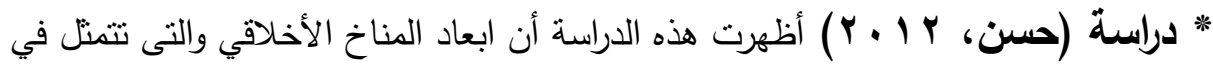
مناخ الرعاية ومناخ القوانين واللوائح ومناخ القواعد فى المستشفيات الخاصة اعلى هن المستشفيات الحكومية. وتوصلت هذه الدراسة إلى يجب على الإدارة العليا فى المستشفيات

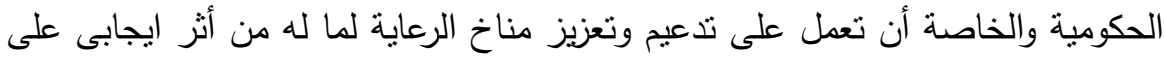
مدركات هيئة التصريض للعدالة التتظيمية بابعادها المختلفة. * دراسة (أصرف، ب ا ـ Y ) أظهرات هذه الدراسة مفهوم رأس المال الفكري واعتباره الثروة الحقيقة التى تضمن للمستشفيات التكيف مع التغير والاستمرار في الأداء المتميز.

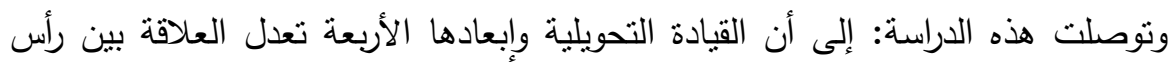


المال الفكري وأبعاد التكيف مع التغيير التنظيمي وتعد هذه النتيجة منطقية حيث انه كلما زادت الدافعية التحويلية كلما زادت درجة التكيف إلى التغيير التنظيمي.

\section{الإسار النظظيه للسوراهة}

مفهوم المناخ الأخلاقي وأبعاده: قام ( Peterson, 2002 ) بتقديم مفهوم المناخ الأخلاقي فهو : "عبارة عن تصور وادراك لما هو السلوك الأخلاقي الصحيح وكيف يجب علينا إدارته فهو يثير الى الثقافه التنظيمية". ولكنه يركز تحديدا على الجو العام الذى يحيط

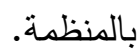
ويشير ( Tsai \& Huang,2007 ) إلى أنه يمكن نوضيح وشرح الأبعاد الخمس للمناخ الأخلاقي كما يلي: البنيز 1-الرعاية ( Caring ) : ويركز هذا البعد على معيار الكرم الأخلاقي ويعتمد على الاهنمام

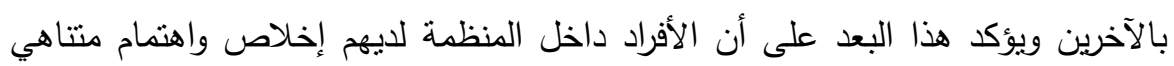
لتحقيق السعادة للأخرين.

r-الاستقلالية ( Independence) ) ويقصد بها إستقإللة الفرد ى تفكيره وتصرفاته وسلوكه حسب معتقداته ومبادئه دون إجبار من جهة العمل لتنفيذ قواعد معينه ويرتكز هذا البعد على معيار المبادئ.

r-القانون والدستور المهنى ( Law \&Code ) يقصد به إلتزام الموظفون بالقوانين وإحترام التعليمات ويرتكز هذا البعد أيضا على معيار المبادئ.

ع-القواعد ( Rules ): يركز هذا البعد على قبول العاملين للقواعد المحددة من قبل المنظمة وأن القرارت التتظيمية موجهة من خلال مجموعة من القواعد الداخلية والمعايير الأخلاقية. ه-الذاتية ( Instrumental ): ويتضمن هذا البعد معيار الأنانية وبعتمد أساساً على تعظيم

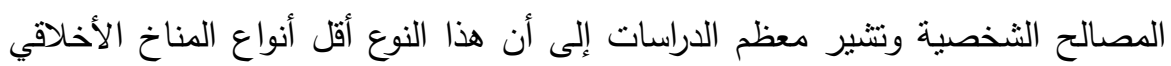
تفضيلاً. (Cullen et.al,2003) 
Intellectual مفهوم رأس المال الفكري ومكوناته: بستحوذ رأس المال الفكري Capital الذي يعبر عن الأصول غير الملموسة في المنظمة على اهتمام كبير في الوقت

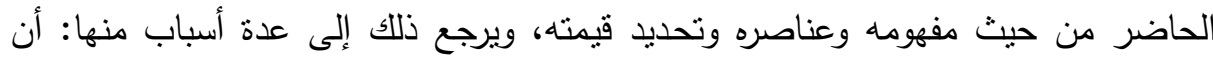

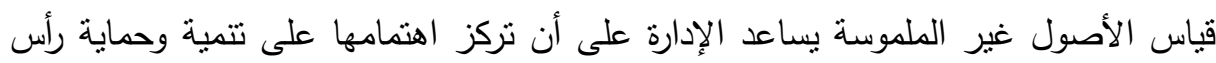

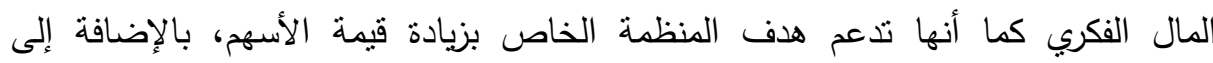
المساعدة على زيادة كفاءة أسواق رأس المال من خلال تزويد المستثرين الحإللين والمرتثقين

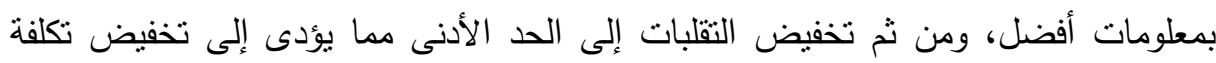

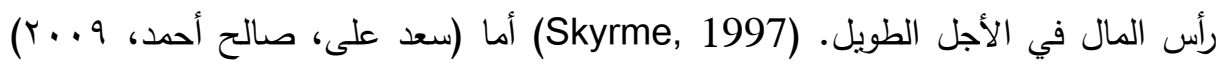
فيعرفوه بأنه: "مجموعة من العاملين الذين يمتلكون قدرات عقلية عناصرها المعرفة والمهارة والخبرة والقيم، يمكن توظيفها واستثمارها في زيادة المساهمات الفكرية، لتحسين أداء عمليات المنظمة، وتطوير مساحة ابداعتها بشكل يحقق لها علاقات فاعلة مع جميع الأطراف المتعاملة معها، ويجعل فرق قيمنها السوقية عن الدفترية كبيراً. يتكون رأس المال الفكري من: رأس المال البشري، ورأس المال الهيكلي، ورأس مالف مال

المقاييس غير النقدية (السلوكية) لرأس المال الفكري (الطنملي، 9. . ب) نقلاً عن (حامد، • الرضا الوظيفي: ويعرف الرضا الوظيفي بأنه حالة سرور أو مشاعر إيجابية تتتج عن

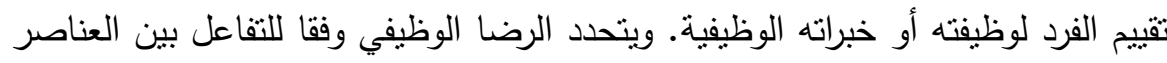
المكونة لبيئة العمل وهى خصائص الوظيفية، وخصائص المنظمة، وخصائص العاملين.

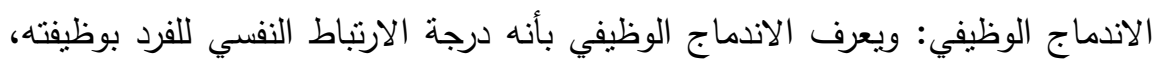

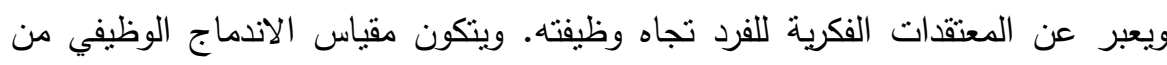
عشرة عبارت على مقياس ليكرت الخماسي تتراوح بين جداً، وغير موافق على الإطلاق.

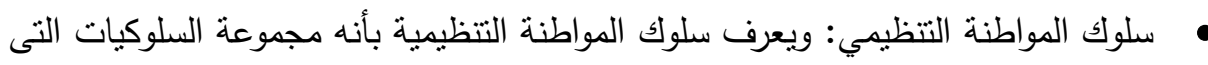
تؤدى اختيارياً بالإضافة الى الدور الرسمي المحدد للفرد، وتساعد على تحقيق الفعالية

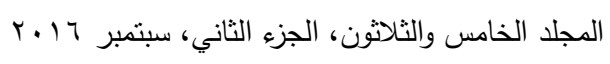


التظيمية، أي أنها سلوكيات إيجابية وبناءة قد يكافأ عليها الفرد وفقاً لنظام المكافآت بالمؤسسة، ويقاس سلوك المواطنة التظظيمية بواسطة مقياس ( Gregerson \& Pearce) والذى يتكون من عشر عبارات على مقياس ليكرت الخماسي.

\section{مجتمع ولمينة الصراسة}

مجتمع الدراسة: يتمثل مجتمع الدراسة في بعض الجامعات الحكومية بكلياتها المختلفة

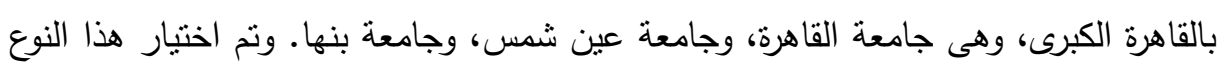
من المنظمات، نظراً لأهمية هذا القطاع الحيوي.

عينة الاراسة: قام الباحثون باختيار عينة عشوائية وممثلة عن: السادة العاملين بالجامعات المصرية الحكومية محل الدراسة، وذلك باستخدام المعادلة التالية لتحديد حجم العينة من نسبة الخطأ المسموح به = الدرجة المعيارية × $\frac{(\cdot, 0-1) \cdot, 0}{\dot{0}} / \times 1,97=., 0$ حيث: ن = حجم العينة. ق = نسبة وجود الظواهر محل الدراسة في العينة، وقد اعنبرتها الباحثة ( •0\%) . نسبة الخطأ المسموح به = (0\%). الدرجة المعيارية = وهي المقابلة لمعامل الثقة الذي تعم به النتائج (90\%)، وبذللك تكون الدرجة المعيارية (197, (1). وبتطبيق هذه المعادلة في ضوء الافتراضات السابقة يكون حجم العينة الممتلة لمجتمع

$$
\text { الدراسة ن = ع ع مفردة. }
$$

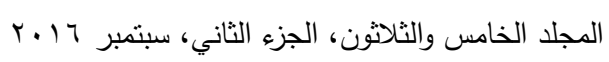


ويوضح الجدول التالي توزيع عينة الدراسة:

جدول(1) - نوزيع عينة الدراسة

\begin{tabular}{|c|c|}
\hline عدد الاستمارات المجمعة & الجامعة \\
\hline 119 & جامعة القاهرة \\
\hline $1 \leq$. & جامعة عين شمس \\
\hline 00 & جامعة بنها \\
\hline 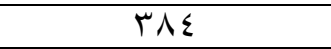 & إجمإلى \\
\hline
\end{tabular}

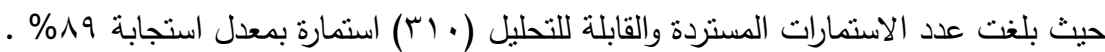
تصميم قائمة الاستقصاء: تم تصميم قائمة استقصاء تضمنت مجموعة من العبارات تقبس اتجاهات أفراد العينة تجاه متغيرات الدراسة، ولتصدم هذه القائمة، فقد قام الباحثون بالإطلاع على عديد من الدراسات السابقة في مجال موضوع الدراسة، بالإضافة إلى قيامها بإجراء لقاءات ميدانية مع السادة الموظفين بالجامعات محل الدراسة، وطرح عليهم بعض الأسئلة

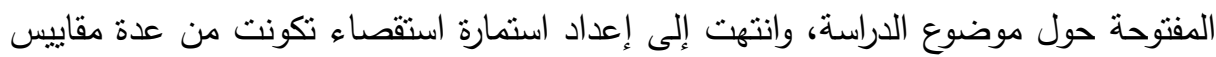
لقياس آراء واتجاهات العينة تجاه متغيرات الدراسة، هي: المناخ الأخلاقي:_وتم قياسه باستخدام مقياس (Victor\& Cullen, 1988) المعدل المكون من \& ا عبارة والذي يقيس الأبعاد الخمسة للمناخ الأخلاقي. ويتكون من البنود من (1-ــ ())،

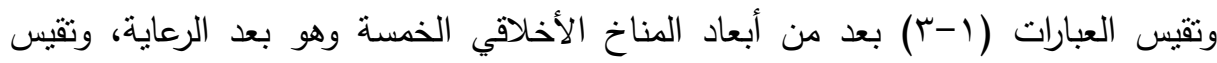

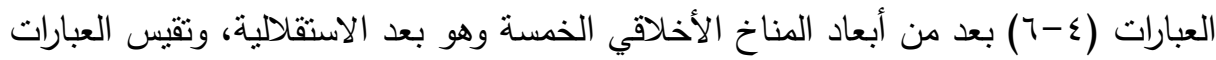

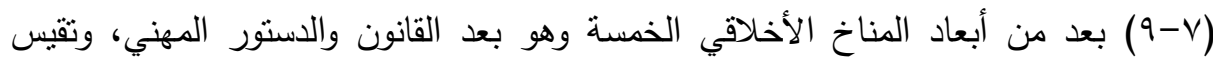
العبارتين (• (1 I I ) بعد من أبعاد المناخ الأخلاقي الخمسة وهو بعد القواعد، وتقيس العبارات

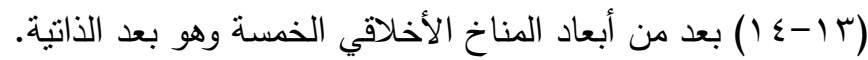

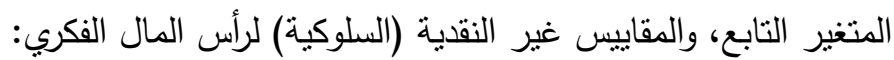
• الرضا الوظيفي: وتم قياسه باستخدام مقياس مكون من خمس عبارات (10 (1 9 (1)

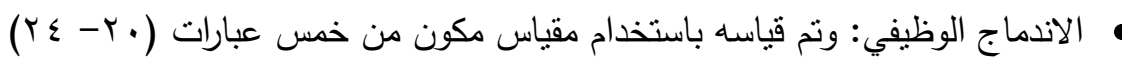

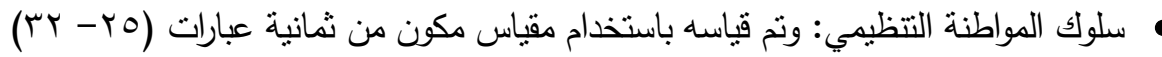


حيث يمثل المناخ الأخلاقي المتغير المستقل لدراسة، والرضا الوظيفي والاندماج الوظيفي وسلوك المواطنة التتظيمي، المتغير التابع والمقاييس غير النقدية (السلوكية) لرأس المال الفكري. وقد صمدت الاستمارة بطريقة "ليكرت" على مقياس خماسي الاتجاه، حيث كان لكل إجابة وزن مرجح، وذللك كما يلي:

\begin{tabular}{|c|c|c|c|c|c|}
\hline غير موافق إطلاقا & غير موافق & محايد & موافق & موافق جدا & درجة الموافقة:- \\
\hline & $r$ & $r$ & $\varepsilon$ & & \\
\hline
\end{tabular}

اختبار الصدق والثبات:أوضح الباحثون فيما يلى نتائج اختبارات الثبات لكل من مقاييس

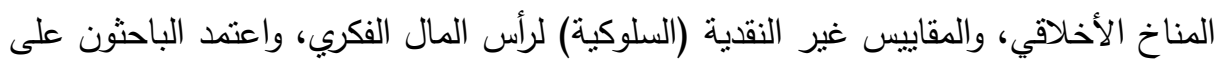

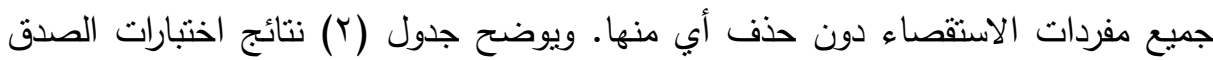
والثبات لاستمارة الاستقصاء ككل.

جدول(ץ): معاملات الصدق والثنات (كرونباخ الفا) لمتغيرات الدراسة

\begin{tabular}{|c|c|c|c|}
\hline الثبات & الصدق (كرونباخ الفا) & عدد العبارات & المتغيرات \\
\hline \%^५ & \%Vo & $1 \leq$ & المناخ الأخلاق \\
\hline$\% 9$ ร & $\% \wedge 9$ & 11 & رأس المال الفكري \\
\hline$\% 9 \xi$ & $\% \wedge 9$ & r & الإجمإلى \\
\hline
\end{tabular}

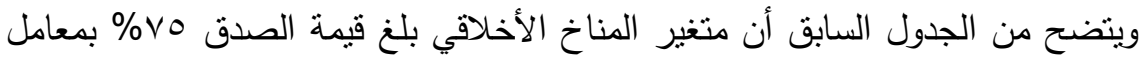

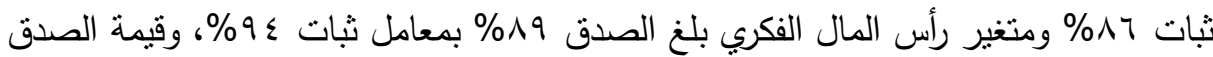

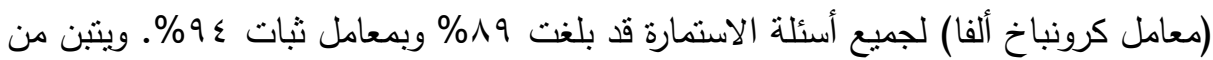
الجدول السابق أن معاملات الثبات لمتغيرات الدراسة تعبر عن نسب عإلبة تصلح لأغراض التحليل الإحصائي والبحث العلمي حيث تشير إلى ثبات استمارة الاستقصاء المستخدمة وإمكانية الوثوق في النتائج التي يمكن التوصل إلها من خلالها.

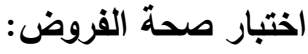
1-نتائج تحليل الانحدار المتعدد. r-نتائج تحليل الانحدار البسيط.

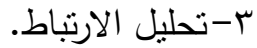


1) نتائج تحليل الانحدار المتعدد: أوضح الباحثون فيما يلي نتائج تحليل الانحدار المتعدد

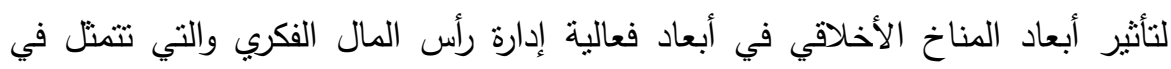
الرضا الوظيفي والاندماج الوظيفي وسلوك المواطنة النتظيمي.

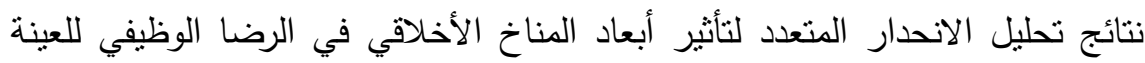

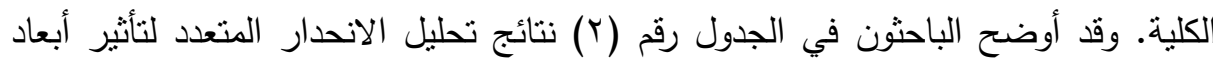

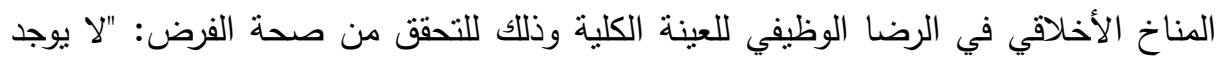
تأثثر ذو دلالة معنوية بين أبعاد المناخ الأخلاقي والتي تتمثل في الرعاية، الاستقلالية، القانون

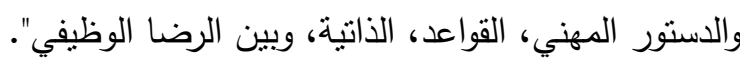
جدول(ץ): نتائج تحليل الانحدار المتعدد لتأثير أبعاد المناخ الأخلاقي في الرضا الوظيفي لإني لل للعينة الكلية

\begin{tabular}{|c|c|c|c|c|c|c|}
\hline \multicolumn{2}{|c|}{ اختبارات " ت " } & \multirow{2}{*}{$\begin{array}{l}\text { المعياري } \\
\text { Beta } \\
\end{array}$} & \multirow{2}{*}{ المعياري الخطى } & \multirow{2}{*}{$\begin{array}{c}\text { الانحدار } \\
\text { B } \\
\end{array}$} & \multirow{2}{*}{ المستقليرة } & \multirow{2}{*}{ التابغير } \\
\hline المعنوية & القيمة & & & & & \\
\hline$\cdot, \cdots 7$ & Y,VAY- & $\cdot, 10 \%-$ & $9, .77$ & $\cdot, 1 \wedge \Gamma_{-}$ & الرعاية & \multirow{5}{*}{ الوظيفي } \\
\hline$\cdot,, r$ & $r, .0 v$ & $\cdot, 101$ & $\cdot, \cdot 7 r$ & $\cdot, 1 \wedge \wedge$ & الاستقلالية & \\
\hline$\cdot, .19$ & $r, r \circ \Lambda$ & $\cdot, 1 \leqslant 1$ & $\cdot, \cdot 9$. & r & والدانتون & \\
\hline$\cdot, \ldots$ & $\Lambda, \vee \top$. & $\cdot, \varepsilon \vee 1$ & $\cdot, \cdot 7$. & $\cdot$, OYT & القواعد & \\
\hline$\cdot, .11$ & $r, \Gamma \wedge I$ & $\cdot, 11 \pi$ & $\cdot, \cdot \leq 0$ & $\cdot, 1 \cdot V$ & الذاتية & \\
\hline \multicolumn{4}{|c|}{ 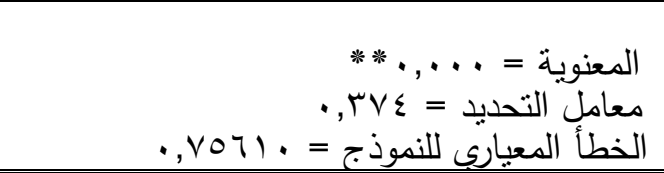 } & \multicolumn{3}{|c|}{ 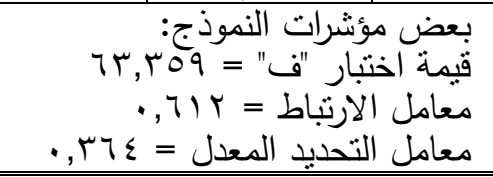 } \\
\hline
\end{tabular}

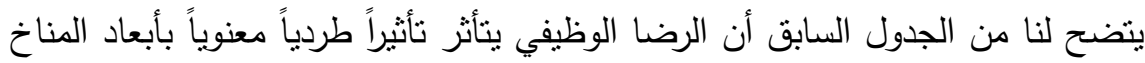

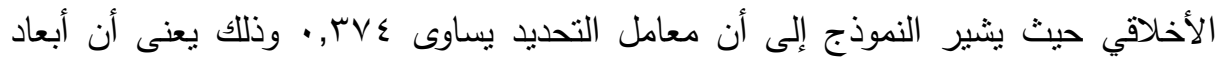

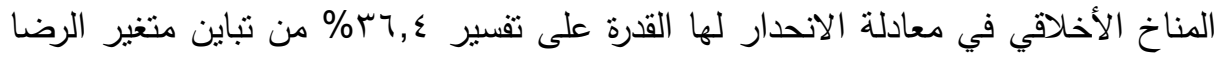


تشير النتائج إلى معنوية النموذج حيث إن قيمة (ف) المحسوبة تساوى وهr,r؟

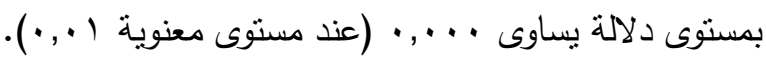

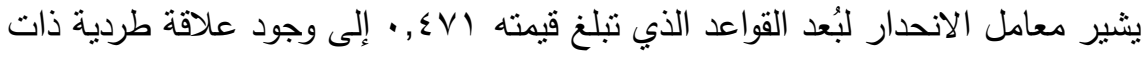

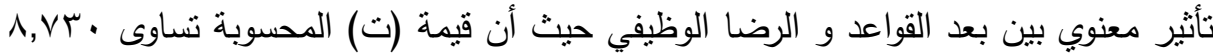

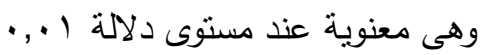

يشير معامل الانحدار لبُعد الاستقلالية الذي تبلغ قيمته 101 , • إلى وجود علاقة طردية

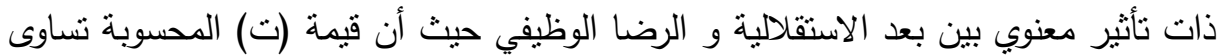

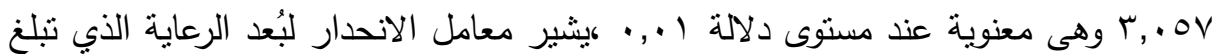

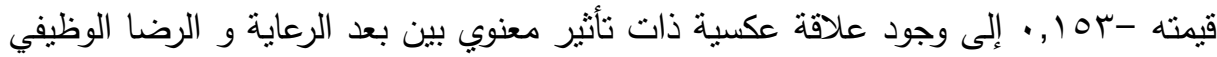

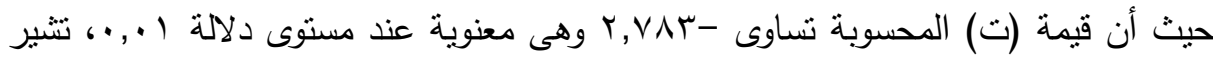

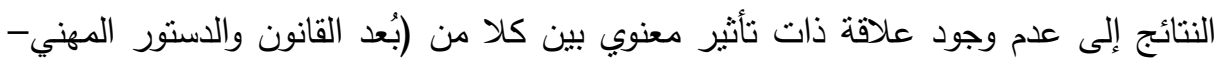
وبُعد الذاتية) والرضا الوظيفي،مما سبق نستتتج رفض الفرض الفرعي جزئيا حيث أنه توجد علاقة ذات تأثثير معنوي بين (القواعد - الاستقلالية - الرعاية) والرضا الوظيفي في حين أنه ليس هناك علاقة ذات تأثنر معنوي بين (القانون والدستور المهني - الذاتية) والرضا الوظين الواتيفي.

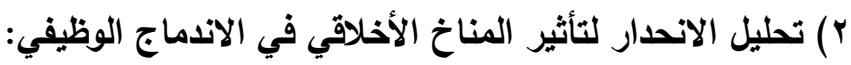

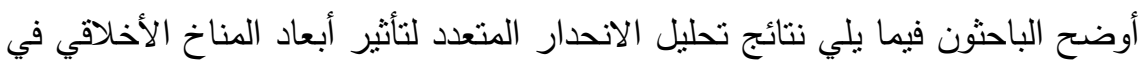
المقياس الكلى الاندماج الوظيفي. 
جدول(؛): نتائج تحليل الانحدار المتعدد لتأثير أبعاد المناخ الأخلاقي في الاندماج الوظيفي

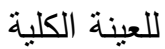

\begin{tabular}{|c|c|c|c|c|c|c|}
\hline \multicolumn{2}{|c|}{ اختبارات " ت " } & \multirow{2}{*}{$\begin{array}{l}\text { المعياري } \\
\text { Beta }\end{array}$} & \multirow{2}{*}{ المعياري } & \multirow{2}{*}{ B الانحدار Bل } & \multirow{2}{*}{ المستفيرة } & \multirow{2}{*}{ التابعير } \\
\hline المعنوية & القيمة & & & & & \\
\hline$\cdot, \ldots$ & $r, 091$ & $\cdot, 199$ &., .0 & $\cdot,|\wedge|$ & الرعابة & \multirow{5}{*}{ الوظيفي } \\
\hline$\cdot, \ldots 0$ & $Y, \wedge 0 \leqslant$ & $\cdot, 1 \leqslant \wedge$ & $\cdot, \cdot \leqslant V$ & $\cdot, 1 \Gamma 0$ & الاستقلالية & \\
\hline & $0, V M T$ & $\cdot, r \leqslant 0$ &., .79 & • rqA & والدانون & \\
\hline$\cdot, \cdot 10$ & $1, \vee \vee q$ &., $.9 \xi$ & $\cdot, \cdot, \leqslant 7$ & $\cdot, \cdot \wedge$. & القواعد & \\
\hline., 100 & $1, \varepsilon Y 0-$ & $\cdot, \cdot 7 \wedge-$ & $\cdot, \cdot{ }^{\circ}$ & $\cdot, \cdot, \leqslant 9-$ & الذاتية & \\
\hline \multicolumn{7}{|c|}{ 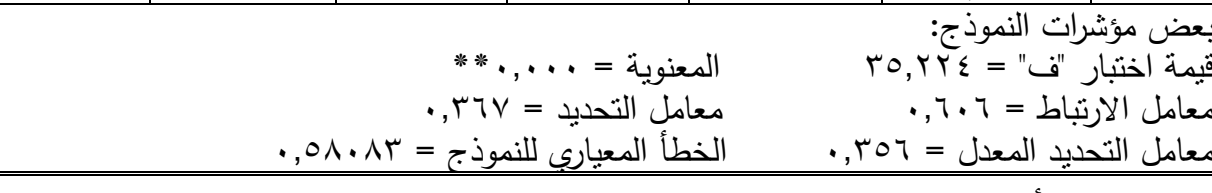 } \\
\hline
\end{tabular}

** تثير إلى أن القيمة المحسوبة ذات دلالة إحصائية عند مسنوى معنوية 0.01

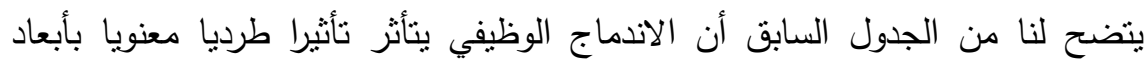

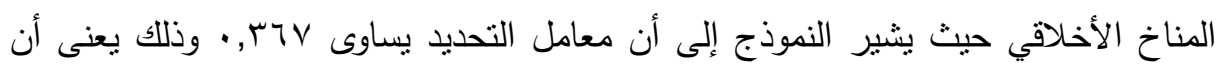

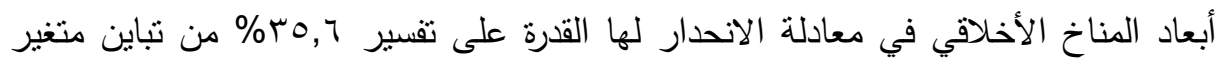
الاندماج الوظيفي.

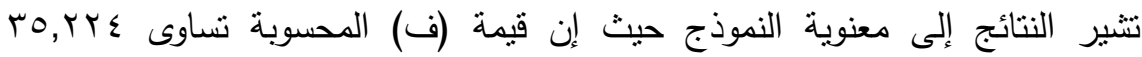

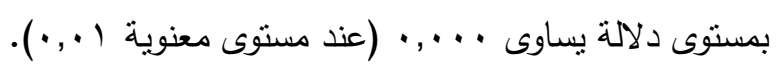

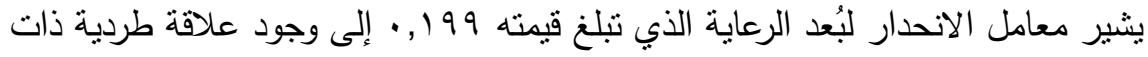

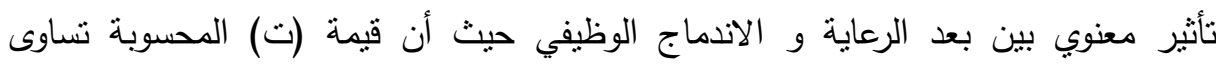

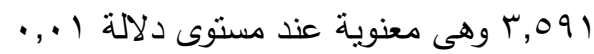
يشير معامل الانحدار لُُعد القانون والدستور المهني الذي تبلغ قيمته هـ؟ب, • إلى وجود علاقة طردية ذات تأثثر معنوي بين بعد القانون والدستور المهني و الاندماج الوظيفي حيث

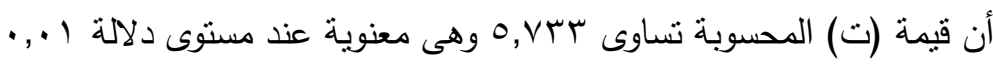


يشير معامل الانحدار لبُعد الاستقلالية الذي تبلغ قيمته ^§ ا, • إلى وجود علاقة طردية

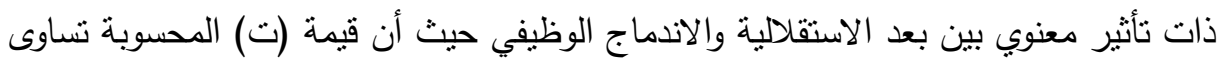

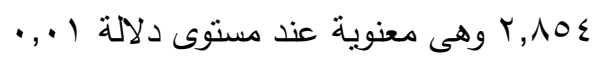
تثتير النتائج إلى عدم وجود علاقة ذات نأثثر معنوي بين كلا من (بُعد القواعد - وبُعد الذاتية) والاندماج الوظيفي. مما سبق نستتنج رفض الفرض الفرعي جزئيا حبث أنه توجد علاقة ذات نأثير معنوي

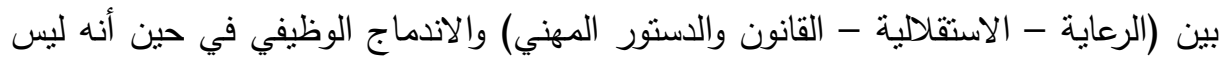
هناك علاقة ذات تأثثر معنوي بين (القواعد - الذاتية) والاندماج الوظيفي.

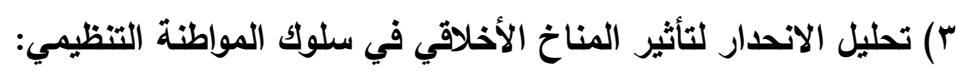

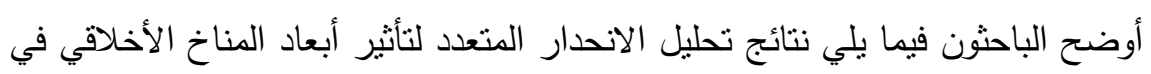
المقياس الكلى في سلوك المواطنة التتظيمي. جدول(ه): نتائج تحليل الانحدار المتعدد لتأثير أبعاد المناخ الأخلاقي في سلوك المواطنة التنظيمي للعينة الكلية

\begin{tabular}{|c|c|c|c|c|c|c|}
\hline \multicolumn{2}{|c|}{ اختبارات " ت " } & \multirow{2}{*}{ المعياري } & \multirow[b]{2}{*}{ المعياري الخطى } & \multirow[b]{2}{*}{ B الاتحدار Bل } & \multirow[b]{2}{*}{ المستقيرة } & \multirow{2}{*}{ التابعير } \\
\hline المغنوي & القيمة & & & & & \\
\hline$\overline{\cdot,, \ldots r}$ & $r, 10 \xi$ & $\cdot, 177$ & $\cdot, \cdot r q$ & $\cdot, I Y Y$ & الرعاية & \multirow{5}{*}{ الوظيفي } \\
\hline$\cdot, \ldots 1$ & $\Gamma, \Gamma \wedge \Lambda$ & $\cdot, 17 \mathrm{~V}$ & $\cdot, \cdot$ T & $\cdot, I Y \mu$ & الاستقلالية & \\
\hline$\cdot, \cdots$ & $\varepsilon, \vee \cdot 0$ & $\cdot, Y \neg 9$ & .,.0r & - ro. & والدانتون & \\
\hline$\cdot, \ldots$ & $0,0 \wedge 7$ & $\cdot, Y \wedge V$ & .,. & $\cdot, 19 V$ & القواعد & \\
\hline$\cdot, 1 \vee 7$ & $1, r \circ V-$ & $\cdot, 71-$ & $\cdot, \cdot Y T$ & -, & الذاتية & \\
\hline & $\cdot, \varepsilon \leqslant \leqslant 7 \pi$ & 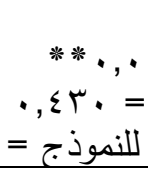 & 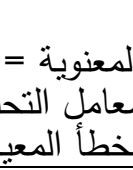 & & 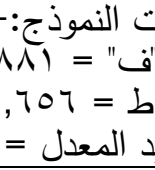 & 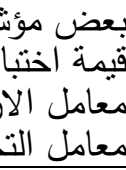 \\
\hline
\end{tabular}


يتضح لنا من الجدول السابق أن سلوك المواطنة التنظيمي يتأثز نأثيراً طردياً معنوياً

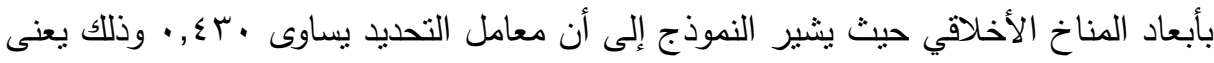

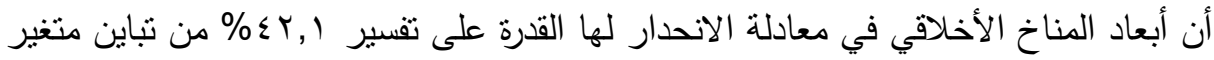

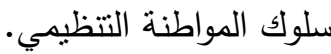

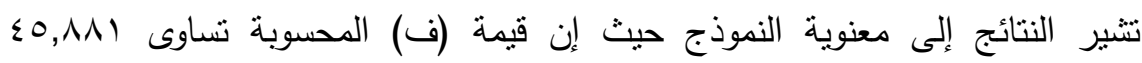

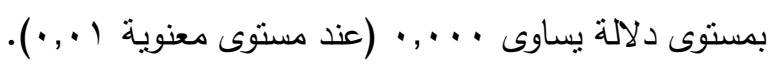

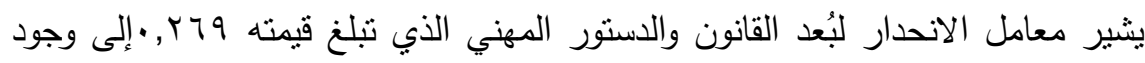

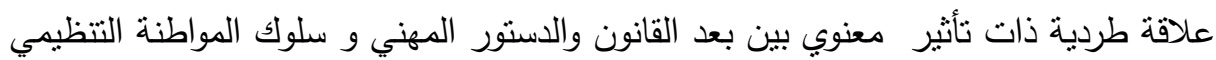

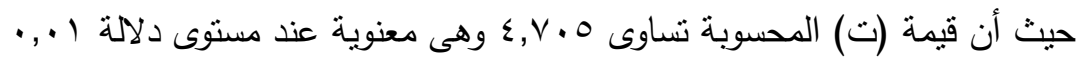

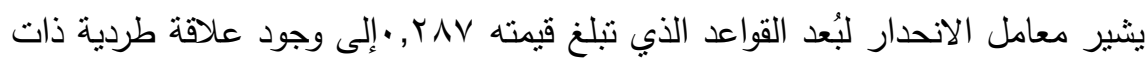

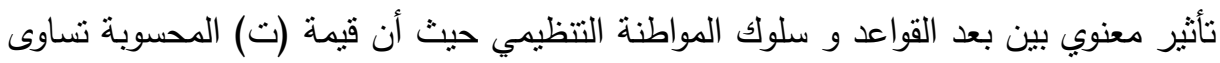

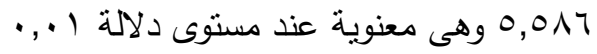

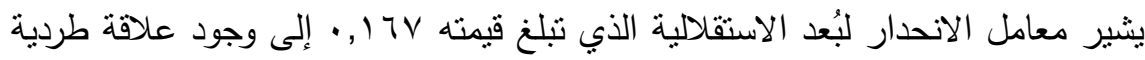

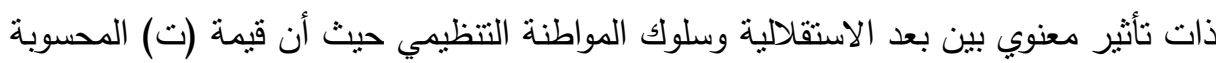

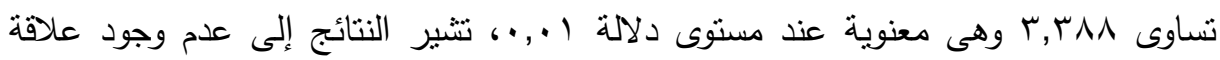

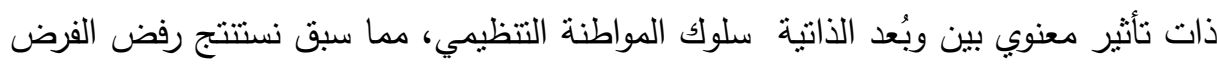
الفرعي حيث أنه نوجد علاقة ذات نأثثر معنوي بين (الرعاية - الاستقلالية - القانون والدستور

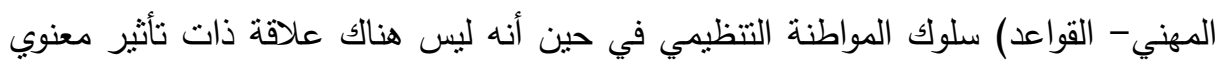
بين (الذاتية) وسلوك المواطنة التنظيمي. تحليل الانحدار البسيط لتأثير مقياس المناخ الأخلاقي الكلي على إدارة رأس المال الفكري: لمعرفة هل أبعاد المناخ الأخلاقي لها تأثير معنوي على فعالية إدارة راس المال الفالفي الفكري قام الباحثون بعمل تحليل انحدار بسيط والذي يهدف لتوضيح العلاقة بين المتغيرين التابع

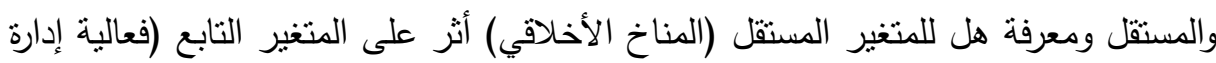

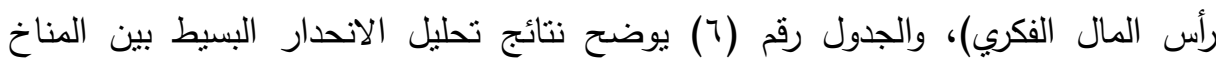
الأخلاقي ككل إدارة رأس المال الفكري: ولمدول 
جدول(†): نتائج تحليل الانحدار البسيط لتأثير مقياس المناخ الأخلاقي الكلي على إدارة رأس

\begin{tabular}{|c|c|c|c|c|c|c|}
\hline & & & & \multicolumn{3}{|c|}{ المال الفكري } \\
\hline \multicolumn{2}{|c|}{ اختبارات " ت " } & \multirow{2}{*}{ المعامل } & \multirow{2}{*}{ المعياري } & \multirow{2}{*}{ الانحدار معل B } & \multirow{2}{*}{ التابغيرات } & \multirow{2}{*}{ المستقِّل } \\
\hline المعنوية & القيمة & & & & & \\
\hline$\cdot, \cdots$ & 10,107 & $\cdot, 70 \leqslant$ & .0. & $\cdot, \vee \bigcirc \wedge$ & إدارة رآس الفكري & الأخلاقَّ \\
\hline$\cdots, \ldots$ & $0, \mu\urcorner \varepsilon$ & - & $\cdot, 1 \wedge 9$ & $1, .1 r$ & - & المقدار \\
\hline \multicolumn{4}{|c|}{ 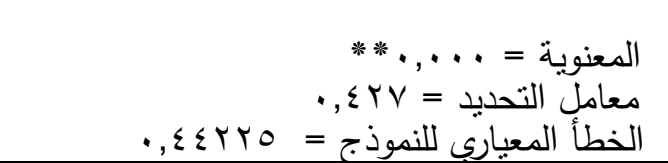 } & \multicolumn{3}{|c|}{ 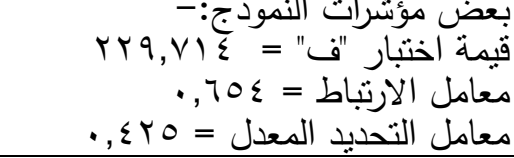 } \\
\hline
\end{tabular}

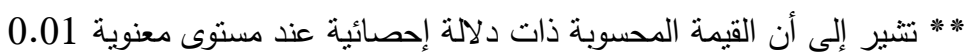

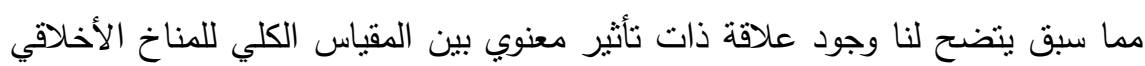

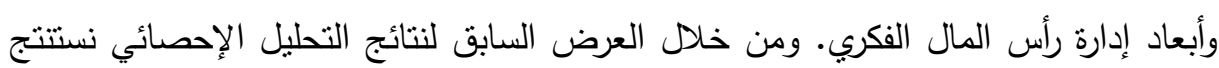
عدم صحة الفرض.

( ) تحليل الارتباط: أوضح الباحثون فيما يلي مصفوفة الارتباط بين متغيرات الدراسة. جدول(V): مصفوفة الارتباط بين أبعاد المناخ الأخلاقي والرضا الوظيفي لإنيا لإنياطي

\begin{tabular}{|c|c|c|c|c|c|c|}
\hline الأتية & القواعد & الالاستون & الاستقلالية & الرعاية & الوظيفي & \\
\hline & & & & $\cdot, .94$ & $1, \ldots$ & الرضا الوظيفي \\
\hline & & & & $1, \ldots$ &., .94 & الرعاية \\
\hline & & & $1, \ldots$ & $* *$, roV & $* *, Y T V$ & الاستقلالية \\
\hline & & $1, \cdots$ & $* *, r \vee v o$ & $* *, 0 . r$ & זדז, •** & القانون والدستور \\
\hline & $1, \cdots$ & $* *, 01 \mathrm{~V}$ & $* *, r \leq r$ & $* *, Y \nearrow$. & $* *, 0 \leq V$ & القواعد \\
\hline $1, \cdots$ & $* \cdot|r|$ & $\cdot, \cdot 1$. & $* \cdot, 1 r q$ & $\begin{array}{c}-\cdot, 1 \leq \vee- \\
* *\end{array}$ & $* *, 19 \vee$ & الذاتية \\
\hline
\end{tabular}

* * تثير إلى أن القيمة المحسوبة ذات دلالة إحصائية عند مستوى معنوية 0.01

يتضح من الجدول السابق: "هناك علاقة ارتباط طردية ذات دلاله إحصائية بين كل بعد إندانه

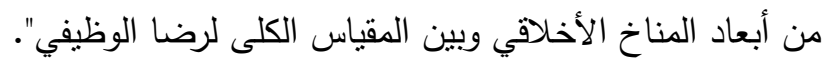


مجلة العلوم البيئية

معهد الدراسات والبحوث البيئية - جامعة عين شمس لبهن

\begin{tabular}{|c|c|c|c|c|c|c|}
\hline الأتية & القواعد & والألقاتون & الاستقلالية & الرعاية & الاندماجي & \\
\hline & & & & ***, $\leqslant 9$. & $1, \ldots$ & الاندماج الوظيفي \\
\hline & & & & $1, \ldots$ & $* *, \leq 9$. & الرعاية \\
\hline & & & $1, \ldots$ & $* *, \Gamma \circ V$ & $* *, r V Y$ & الاستقلالية \\
\hline & & $1, \ldots$ & $* *$, rVo & $* *, 0, r$ & $* *, 0 \wedge 1$ & القانون والدستور \\
\hline & $1, \cdots$ & $* *, 01 \mathrm{~V}$ & $* *, r \leq r$ & **, , Y . & $\begin{array}{c}\cdot, r V Y \\
* *\end{array}$ & القواعد \\
\hline $1, \ldots$ & $*,|| Y \mid$ & $\cdot, \cdot 1$ & $*, 1 Y 9$ & $* *, 1 \leq V$ & $* *, 0$. & الذاتية \\
\hline
\end{tabular}

** تشبر إلى أن القيمة المحسوبة ذات دلالة إحصائية عند مستوى معنوية 0.01

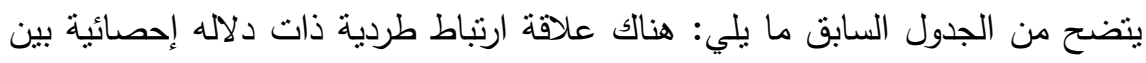

كل بعد من أبعاد المناخ الأخلاقي وبين المقياس الكلى للاندماج الوظيفي.

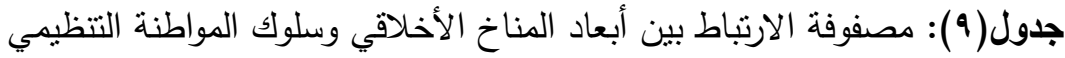

\begin{tabular}{|c|c|c|c|c|c|c|}
\hline الأتية & القواعد & والألقانون المهني & الاستقلالية & الرعاية & المبلوكتة & \\
\hline & & & & $* *, \leq V \backslash$ & $1, \cdots$ & سلوك المواطنة \\
\hline & & & & $1, \ldots$ & $* *, \leq \vee 1$ & الرعاية \\
\hline & & & $1, \ldots$ & $* *, \mathrm{r} \circ \mathrm{V}$ & $* *, r \wedge r$ & الاستقلالية \\
\hline & & $1, \ldots$ & $* *, r \vee v$ & $* *, 0, r$ & $* *$, or. & القانون والدستور \\
\hline & $1, \ldots$ & $* *, 01 \mathrm{~V}$ & $* *, r \leq r$ & $* *, Y \uparrow$ & $* *, \leq 9 \leq$ & القواعد \\
\hline $1, \ldots$ & $*,|r|$ & $\cdot, \cdot 1 \cdot$ & $* \cdot, 1 Y 9$ & $* *-,, 1 \leq V-$ & $* *, \cdot T V$ & الذاتية \\
\hline
\end{tabular}

* * تشير إلى أن القيمة المحسوبة ذات دلالة إحصائية عند مستوى معنوية 0.01

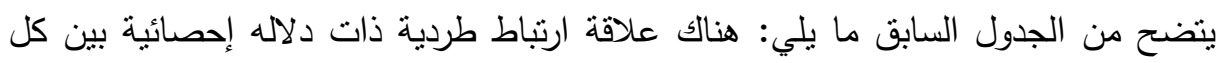
بعد من أبعاد المناخ الأخلاقي وبين المقياس الكلى سلوك المواطنة التنظيمي. 
جدول( • 1): مصفوفة الارتباط بين متغيرات الدراسة

\begin{tabular}{|c|c|c|}
\hline المقياس الكلي إدارة رأس & المقياس الأخلاقي المناخ & \\
\hline$* * *, 709$ & $1, \ldots$ & المقياس الكلى المناخ الآخلاقى \\
\hline $1, \cdots$ & $* *, 709$ & المقياس الكلى إدارة رأس المال الفكري \\
\hline
\end{tabular}

** *تير إلى أن القيمة المحسوبة ذات دلالة إحصائية عند مسنوى معنوية 0.01

** *تير إلى أن القيمة المحسوبة ذات دلالة إحصائية عند مستوى معنوية ه, .

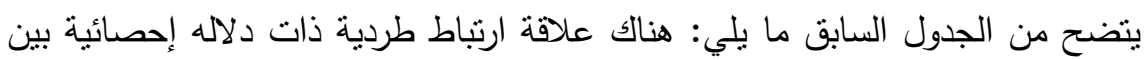

المقياس الكلي للمناخ الأخلاقي وبين المقياس الكلى إدارة رأس المال الفكري.

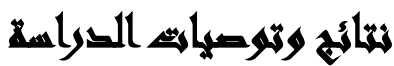

يتتاول هذا الجزء من المبحث أهم نتائج الدراسة الميدانية المتعلقة بمتغيرات الدراسة،

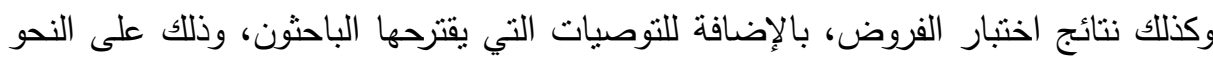

$$
\begin{aligned}
& \text { التالى: } \\
& \text { أولاً:-- النتائج } \\
& \text { ثانياً:- التوصيات } \\
& \text { ثالثاً:- بحوث مستقبلية }
\end{aligned}
$$

النتائج:

درجة مصداقية النتائج المحققة على جميع مفردات الاستقصاء دون حذف أي منها باستخدام معامل ألفا كرونباخ.

قيمة معامل ألفا كرونباخ لجميع مفردات استمارة الاستقصاء أكبر من 9 , •، وبالتالى فإن

$$
\text { المقاييس المستخدمة تتسم بالثبات. }
$$

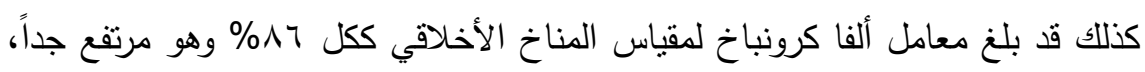

$$
\text { بما يعكس ثنات المقياس الكلي. }
$$

كذلك قد بلغ معامل ألفا كرونباخ لمقياس إدارة رأس المال الفكري ؟ ؟ \% وهو مرتفع جداً

$$
\text { بما يعكس ثبات المقياس الكلي. }
$$

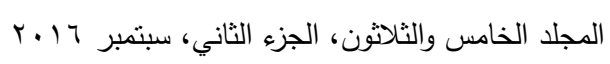


يتضح من ذلك أن قيمة معامل الثبات للمقاييس المستخدمة في الدراسة كلها بلغت ؟ \% ؛ وبالتإلى فإن المقاييس المستخدمة تتسم بالثبات. ( ) نتائج اختبارات صحة الفروض:

وجود علاقة ذات نأثثر معنوي بين الرضا الوظيفي، والمناخ الأخلاقي فيما يتعلق بكل

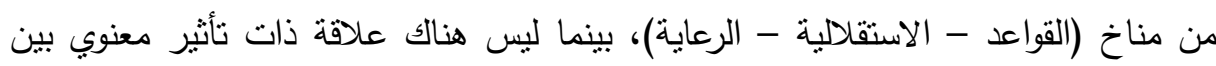

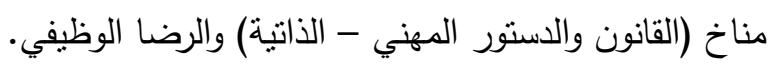
وجود علاقة ذات تأثير معنوي بين الاندماج الوظيفي، والمناخ الأخلاقي فيما يتعلق بكل الوطل

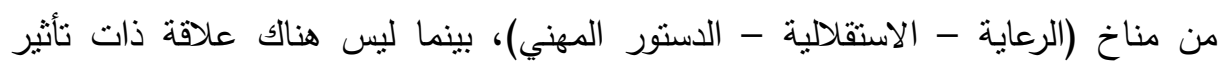
معنوي بين مناخ (القواعد- الذاتية) والاندماج الوظيفي.

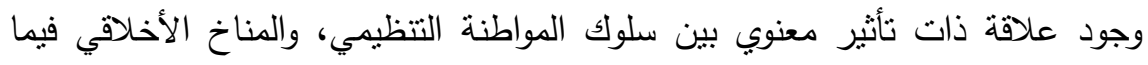

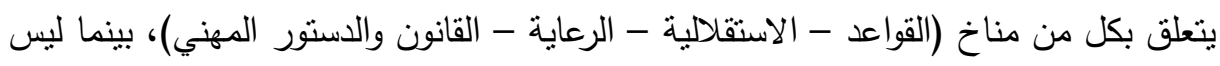
هناك علاقة ذات نأثثر معنوي بين مناخ (الذاتية) وسلوك المواطنة التنظيمي. r) نتائج اختبار صحة الفرض الرئيسي: تم رفض الفرض الرئيسي للدراسة (لا يوجد تأثير ذو دلالة معنوية بين أبعاد المناخ

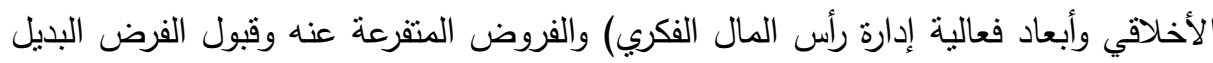
(يوجد تأثير ذو دلالة معنوية بين أبعاد المناخ الأخلاقي وأبعاد فعالية إدارة رأس المال الفرال الفكري). حيث أكدت النتائج على أنه: وجود علاقة ذات تأثير معنوي بين المقياس الكلي للمناخ الأخلاقي والمقياس الكلي لأبعاد إدارة رأس المال الفكري. وجود علاقة ارتباط طردية ذات دلاله إحصائية بين المقياس الكلي للمناخ الأخلاقي وبين الماني المقياس الكلى إدارة رأس المال الفكري. 
التوصيات: بناء على نتائج الدراسة الميدانية، يرى الباحثون أن نواحي معينه يجب الاهتمام

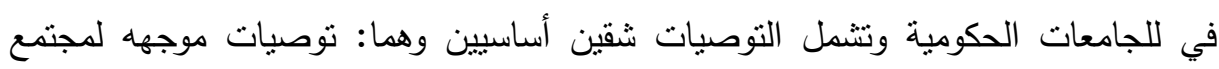
الدراسة، وتوصيات ببحوث مستقبلية وذلك على النحو التالي: توصيات خاصة بمجتمع الدراسة:

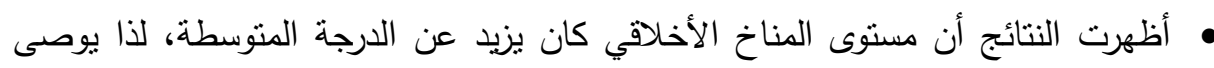

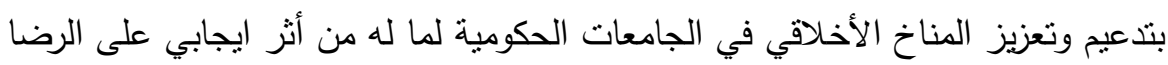
الوظيفي والاندماج الوظيفي وممارسة سلوكيات المواطنة التنظيمي، وذللك عن طريق ما

عمل ندوات وورش عمل لتوضيح أهية المناخ الأخلاقي، وضع برنامج تدريبي لتدعيم ممارسة أبعاد المناخ الأخلاقي التي تتمثل في (الرعاية - الاستقلالية- القواعد - القانون والدستور المهني).

يجب على الإدارة العليا في الجامعات الحكومية أن تعمل على الحد من مناخ الذاتية بقدر المستطاع لما له من أثر سلبي على الرضا الوظيفي والاندماج الوظيفي وممارسة سلوكيات المواطنة التنظيمي ، وذلك عن طريق ما يلي:

تطبيق نظام فرق العمل للحد من ظهور الأنانية وتحقيق المصالح الثخصية على ملى حساب الآخرين. أن تقوم إدارة الموارد البشرية في الجامعات بنطوير استراتيجيات عملية الاختيار والتعيين بحيث تتضمن اختبارات عن التقييم الأخلاقي والثخصية الأخلاقية. • يجب على الإدارة العليا في الجامعات الحكومية أن تعمل على استثمار الأصول الفكرية الغير ملموسة وتتميتها وتطويرها، وذلك عن طريق ما يلي:

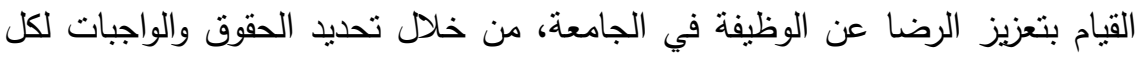

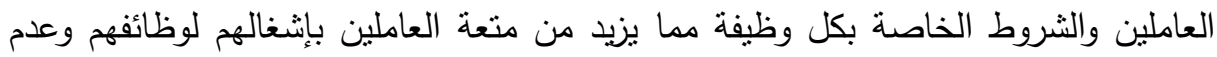
الثُعور بالضيق والملل. 
تمهيد الطريق للاندماج وذللك من خلال التركيز بدرجة أكبر على غرس روح الاندماج

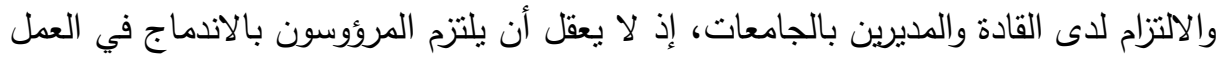

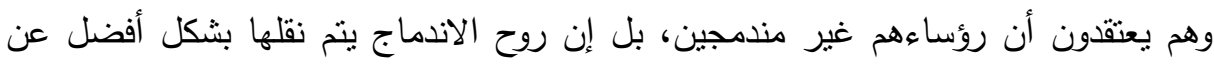
طريق الاقتداء بالرؤساء والقادة. تدعيم ممارسة سلوك المواطنة التنظيمي وذلك من خلال إيجاد برامج تدريبية له، وجعل الحصول عليها من منطلبات الترقية للمراتب الأعلى للعاملين بالجامعات.

توصيات ببحوث مستقبلية:-

- دراسة محددات تؤثر في المناخ الأخلاقي للمنظمات منل القيادة الملهمة. - دراسة عن كيفية تقييم إدارة رأس المال الفكري في المؤسسات الحكومية. - دراسة العلاقة بين المناخ الأخلاقي ورأس المال الفكري في قطاعات أخرى منل قطاع المؤسئ

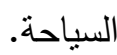

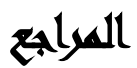

أحمد على محمد حسن(Y Y Y): "العدالة التنظيمية كمنغير وسيط في العلاقة بين المناخ الأخلاقي للمنظمة وسلوكيات المواطنة النتظيمية "، رسالة ماجستير ، كلية تجارة ، جامعة عين

شمس.

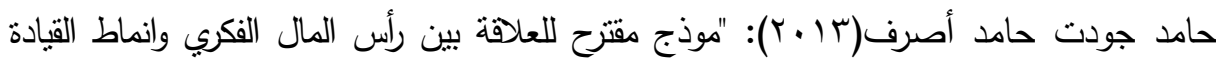
والتكيف مع التغيير" بالتطبيق على المستشفيات فى قطاع غزة ، رسالة دكتوراه ، كلية تجارة ، جامعة عين شمس. دعاء ممدوح محمد شلبى(Y ( ب): "العلاقة بين المناخ الأخلاقي والتفكير الابتكارى فى ظل

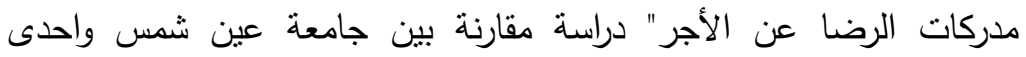
الجامعات الخاصة. رسالة ماجستير ، كلية تجارة ، جامعة عين شمس.

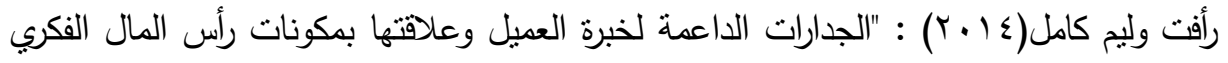
فى البنوك التجارية المصرية": نموذج مقترح، المجلة العلمية للاقتصاد والتجارة، 
سيد محمود الخولي وآخرون

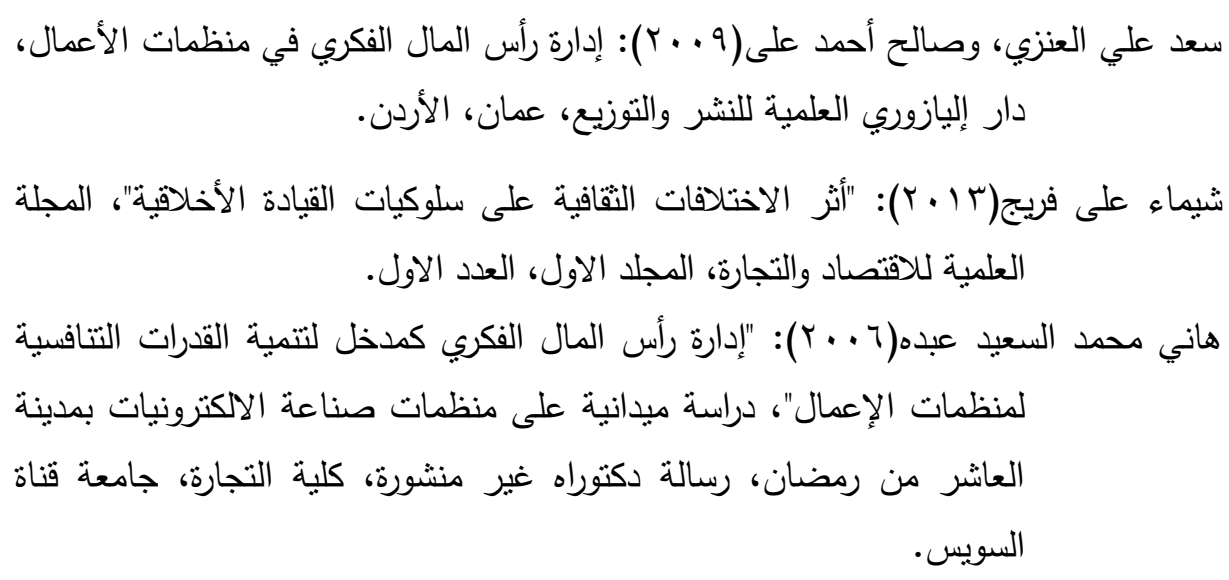

Al- Ali, N. (2003): "Comprehensive Intellectual Capital Management: Step by Step", John Wily \& Sons, Inc, Hoboken, New Jersey, U.S.A.

Appelbaum, S. Deguire and M. Lay (2005): 'The Relationship of Ethical Climate to Deviant Workplace Behavior' Corporate Governance 5(4), 43-55.

Babin, B. J. (2004): Buyer Reactions to Ethical Beliefs in the Retail Environment. Journal of Business Research, Vol.57, N. 10, pp $1155-1163$..

Brower, H. H. and Shrader, C. B. (2000): Moral reasoning and ethical climate: Not - for - profit vs. For- profit boards of directors. Journal of Business Ethics, 26, 147-167.

Budd, J,W. Employment With a human face: Balamcingefficiency, equity and voice, Electronic Version. Ithaca, NY: ILR Press,(2004).

Cullen, J.B.; Parboteeah, K., and Victor, B. (2003): The Effects of Ethical Climates on Organizational Commitment: A two study analysis, Journal of Business Ethics, 46, 127 -141.

Daft L. Richard (2003): Management, $6^{\text {th }}$. Ed., Thompson SouthWestern Publishing Co.

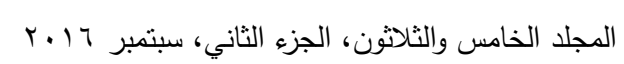




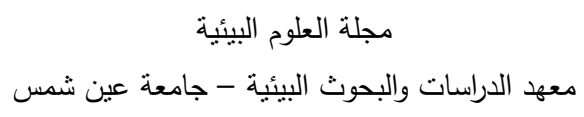

Skyrme, D. (1997): "Measurig The Value of Knowledge: metrics for The Knowledge Based Business" Business Intelligence, London.

Tsai, M.T. and Huang, C.C. (2007): The Relationship among Ethical Climate Types, Facets of Job Satisfaction, and The Three components of organizational commitment: A study of nurses in taiwan 'Journal of Business Ethics, vol.80, N.3 pp $565-581$.

Victor, B. and J. B. Cullen: (1988): A Theory and Measureof Ethical Climate in Organizations in W. C. Frederick (ed.), Research in Corporate Social Performance and Policy (JAI Press, Greenwich CT), pp. 51-71.

\title{
THE IMPACT OF ETHICAL CLIMATE TO IMPROVE THE EFFICIENCY AND EFFECTIVENESS OF THE MANAGEMENT OF INTELLECTUAL CAPITAL
}

\author{
Al-Kholy, S. M. ${ }^{(1)}$; Gebril, Magda $^{(1)}$; Hany, A. F. ${ }^{(2)}$ \\ and Azouz, Fatma, $M$.
}

1) Faculty of Commerce, Ain Shams University 2) Institute of Environmental Studies \& Research, Ain Shams University

\begin{abstract}
The present study attempts to identify the shortness exists in management of the intellectual capital among employees of governmental universities being represented in job satisfaction, job adaptation an integration, in addition to organizational citizenship behavior as non-concrete elements for intellectual capital management resulted in the unconcern of ethical climate among universities employees.

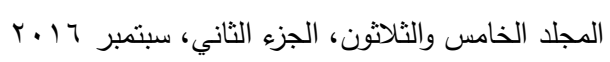




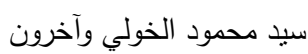

The study concludes the following: The main hypothesis of study is rejected (there is no significant impact between dimensions of the ethical climate and dimensions of the intellectual capital management's effectiveness) and so the branch-hypotheses; while the alternative hypothesis is approved (there is a significant impact between dimensions of the ethical climate and dimensions of the intellectual capital management's effectiveness).

The study results indicate the following: There is no significant impact between the total measurement of ethical climate and the total measurement of dimensions of the intellectual capital management. There is a direct statistical significant relationship between the total measurement of ethical climate and the total measurement of the intellectual capital management. 